\title{
The Study of the "Size Effect" on the Market Efficiency and the Market Anomalies in NASDAQ
}

\author{
Siling Pan ${ }^{1 *}$, Congrui $\mathrm{Yin}^{2}, \mathrm{Yu} \mathrm{Ai}^{3}$, Zhiheng $\mathrm{Li}^{4}$ \\ ${ }^{1}$ Hangzhou commerce school, Zhejiang Gongshang University, Hangzhou, Zhejiang, 310000, China, \\ katherine2899@qq.com \\ ${ }^{2}$ Chongqing Gongshang University, Chongqing, 400067, China, cyin47@uwo.ca \\ ${ }^{3}$ Chongqing Gongshang University, Chongqing, 400067, China, 1140810883@qq.com \\ ${ }^{4}$ Auburn University, Auburn, Alabama, 36849, USA, 1440419945@qq.com
}

\begin{abstract}
Since the Efficient Market Hypothesis was proposed by Eugene Fama in 1970, it has been continuously challenged by various market anomalies and financial empirical evidence in the U.S. stock market. Inspired by the reserve effect, the momentum effect and the effect size discovered by De Bondt and Thaler, Jegadeesh and Titmanand Banz respectively, this paper reasonably speculates that there is also a "size effect"[1] on both the degree of market efficiency and the frequency of market anomalies [2]. Taking the NASDAQ stock exchange as the research object, this paper uses the VR ratio method proposed by Lo and MacKinlay to test the efficiency of the Nasdaq market, and then uses event analysis and Debondt and Thaler methods to separate the abnormal frequency of the Nasdaq market and test whether there is "scale effect". This paper concludes that there is a "size effect" in the degree of market efficiency and the frequency of market anomalies in NASDAQ. Finally, this paper proposes an investment strategy based on the findings.
\end{abstract}

Keywords: Efficient Market Hypothesis (EMH), market anomalies, VR ratio, size effect

\section{INTRODUCTION}

The emergence of the Efficient Market Hypothesis (EMH) theory roots in two studies about Random Walk Hypothesis. In the paper "The Theory of Speculation: The Origins of Modern Finance", Bachelier proposed the Random Walk Hypothesis (RWH), and indicated that the unpredictable trend of commodities' price was random and unpredictable. In 1933, Coles believed that stock prices in the U.S. stock market conformed to the Random Walk Hypothesis. Then, on the basis of summarizing the previous studies on the random walk hypothesis and market efficiency, Eugene Fama became the first person to systematically put forward the efficient market hypothesis (EMH) in his paper "Efficient Capital Markets: A Review of Theory and Empirical Work".

The EMH believes that the financial market is efficient if the price of securities can accurately reflect all their relevant information, while the stock market is only considered efficient if the stock price does not fluctuate abnormally after a set of information about the stock is revealed. Generally, under the Efficient Market Hypothesis, the efficient market is characterized by the absence of both the overreaction to the information and the undervalued of the stock price.

The market is divided into three levels by the efficient market hypothesis in accordance with the market strength, namely, weak efficient market, semi-strong efficient market, and strong efficient market.

In the weak efficient market, the price of assets contains all the historical information in the past. Through the mining and analysis of historical data in the past, this paper summarizes the law and mode of the price change by means of the technical analysis method.

The strong efficient market is an ideal market and hardly exists in the real world, where the price of assets has fully reflected the historical information, public information and non-public information. That is to say, it contains all the information, and any technical analysis and fundamental analysis are futile in this market.

In the following 40 years after Fama proposed the market efficiency hypothesis, the validation of the Efficient Market Hypothesis on the US stock market had been continuously challenged by kinds of market anomalies and financial empirical evidence. 
First, Lo and Mackinlay found that the New York Stock Exchange (NYSE) did not satisfy with the weak form of Efficient MarketHypothesis. In the paper "Stock Market Prices Do Not Follow Random Walks: Evidence from a Simple Specification Test", Lo and Mackinley put forward VR ratio to judge whether the stock listing in New York Stock Exchange (NYSE) from 1962 to 1985 are in line with the random walk hypothesis, and it is concluded that New York Stock Exchange (NYSE) does not satisfy the weak form of the efficient market hypothesis.

Under the premise of invalid market, there are two kinds of anomalies in the market. One is the reverse effect. De bond and Thaler (1985) found that the performance of the "winner portfolio" composed of the best performing stocks in the past five years and the "loser portfolio" composed of the worst performing stocks in the past five years reversed in the following three years [3]. Specifically, after risk adjustment, it is found that the loser portfolio maintains a positive cumulative abnormal surplus (CAR) in the next three years. On the contrary, we find that winner's portfolio keeps positive CAR at the beginning of the period while keeps negative CAR during the rest of the observation period. Then, reserve effect is defined as the phenomenon that stock performance reverses in the medium term and keeps a new trend in the long term.

The other market anomaly is called momentum effect. By using the approach similar to that of De Bond and Thaler (1985), Jegadeesh and Titman (1993) found that the stock performance of the stock listing in New York Stock Exchange (NYSE) was positively correlated with his previous performance in the past 3 to 12 months. Specifically, after risk adjustment, the "winner portfolio" maintains a positive CAR in the following 36 months and the "loser portfolio" maintains a negative CAR in the following 36 months [4]. The phenomenon of stock performance maintaining a good or bad trend for a long time is defined as reserve effect.

Later, the discovery of scale effect makes it reasonable to speculate that the efficiency and abnormal frequency of American stock market change with the change of company size. The findings of scale effect show that the size of the firm is a potential factor affecting market efficiency and market abnormal frequency. Banz (1981) summarized the stock performance of the companies listed on the New York Stock Exchange (NYSE) from 1936 to 1975 and classified them according to the size of the company. He found that the smaller the size of the company, the more obvious the negative correlation between the risk adjusted return [5], that is, the return on investment decreased with the increase of the size of the company.
Therefore, it is reasonable to speculate that the "scale effect" of the US stock market has an impact on market efficiency and market anomalies. In this paper, we divide the sample companies into several levels according to the market value, and then use Lo and McKinley's VR ratio method and De bond and Thaler's method to estimate the market efficiency of NASDAQ and judge whether there are market anomalies [6].

\section{METHODOLOGY AND DATA ORIGINATION}

\subsection{Selection of the Studied Period}

To exclude the negative impact on the NASDAQ that brought by extreme macroeconomic event, this paper chooses the quiet period [7] in the stock market, which is from Jan. 1st, 2009, to Dec 31st, 2019 as the studied period, which is divided into two 5-year studied periods so as to have more observation, and the first study period is from January 1st, 2009 to December 31st, 2013 and the second study period is from Jan 1st, 2014 to December 31st, 2018 (see Table 1).

Table 1 Division of the Gross Studies Period

\begin{tabular}{llll}
\hline $\begin{array}{l}\text { Studied } \\
\text { Period 1 }\end{array}$ & & $\begin{array}{l}\text { Studied } \\
\text { Period 2 }\end{array}$ & \\
\hline Jan 1, Dec 31, & Dec 31, & Dec 31, & Dec 31, \\
20092010 & 2013 & 2015 & 2018 \\
\hline
\end{tabular}

\subsection{Stratification of Companies}

The traditional classification divides companies into four categories, namely, the large capital with market value greater than 10 billion, the mid-capital with market value between 2-10 billion, micro-cap with market value between 50 million and 2 billion, and the nano cap with market value less than 50 million. However, in the practice of sampling, there are 2 disadvantages of applying the traditional stratification:

\subsubsection{It is hard to illuminate the "size effect" based on only four levels.}

2.2.2. Within the traditional stratification, the companies fall into the category of the mid-cap and micro-cap level are much more than the companies located in the large-cap level and nano-cap level, which is likely to cause statistically bias.

Therefore, based on the actual sampling situation, this paper improves the traditional stratification and reasonably divides the company into 6 levels, so that the number of companies available for sampling in each level is basically the same [8] 
Table 2 Division of Corporations Group

\begin{tabular}{|c|c|c|}
\hline Level 1 & Large Corporations Group & AMC [9]> 20 Billions \\
\hline Level 2 & Middle Large Corporations Group & $\begin{array}{l}5 \text { Billions < AMC }<20 \\
\text { Billions }\end{array}$ \\
\hline Level 3 & Middle Corporation Group & 1 Billions $<$ AMC $<5$ Billions \\
\hline Level 4 & Small Corporation Group & $\begin{array}{l}500 \text { Millions < AMC }<1 \\
\text { Billion }\end{array}$ \\
\hline Level 5 & Micro Small Corporation Group & $\begin{array}{l}50 \text { Millions }<\text { AMC }<500 \\
\text { Millions }\end{array}$ \\
\hline Level 6 & Nano Small Corporation Group & AMC $<50$ Millions \\
\hline
\end{tabular}

\subsection{Sampling Methods and Data Origination}

1. Number of Companies in Each Level: there are 10 qualified companies in each level. Each qualified company is given tests on two studied periods for having more observations.

2. Sampling Method: 1-2 qualified companies in each level are selected on each page of investing.com, which means 6-12 qualified companies are selected on each page.

3. Qualified company shall meet the requirement as follows:

a. listed before 2019, Jan 1st.

b. the data regarding the market capitalization data and price [10] of the company in two studied periods shall be accessible in Yahoo! Finance.

c. within the same page in investing.com, the first letter of the symbol [11] for each companyshall be different for ensuring the randomness of the sampling.

d. the company shall fall into the same level in the two studied periods in order to avoid the momentum effect caused by the rapid group or rapid decline of market capitalization.

4. Data Origination: all the companies used in this paper originates from the components of NASDAQ composition provided by investing.com [12]. The components of NASDAQ composition were divided into 6 pages in investing.com. The data regarding the market capitalization, daily close price is from Yahoo! Finance.

\subsection{Model Building}

According to Lo and MacKinlay (1988), if the price change of stock in the study period is a random process, which means the price series shall satisfy thefollowing formula to follow the random walk hypothesis:

$\operatorname{Var}\left(P_{t}-P_{t-k}\right)=\mathrm{k} * \operatorname{Var}\left(P_{t}-P_{t-1}\right)$ Where Pt-1 as the closed price of the last trading day and Pt-k as the closed price $\mathrm{k}$ trading day before

\subsection{Statistic}

Based on the VR ratio initiated by Lo and MacKinlay (1988), the statistic for the VR ratio test is as follows:

$$
Z(k)=\frac{V R(k)}{\sqrt{\sigma^{2}(k)}}-1 \sim N(0.1)
$$

Where

$$
\operatorname{VR}(k)=\frac{\operatorname{Var}\left(P_{t}-P_{t-k}\right)}{k * \operatorname{Var}\left(P_{t}-P_{t-1}\right)}, k=5,10,20,40,80
$$

Where $\mathrm{Pt}-1$ as the closed price of the last trading day and $\mathrm{Pt}-\mathrm{k}$ as the closed price $\mathrm{k}$ trading day before And

$$
\sigma^{2}(k)=\frac{(2 k-1)(2 k-2)}{3 k n}
$$

Where $\mathrm{k}$ as lag period, $\mathrm{n}$ as total trading days in the studied period [13].

\subsection{Market Anomalies Test}

\subsubsection{Watch Windows and Event Windows in the Market Anomalies Test}

Based on De Bond and Thaler's method on identifying the market anomalies (1985), the first twoyears of the study are defined as the "watch window" and the following three years of the study are defined as the "event window" (see Table 3).

Table 3 Division of the Studies Period

\begin{tabular}{|l|l|l|l|}
\hline Watch & Event & Watch & Event \\
Windo & Window 1 & Windo & Window 2 \\
w 1 & w & \\
\hline \multicolumn{2}{|l|}{ Studied Period 1 } & \multicolumn{2}{|c|}{ Studied Period 2 } \\
\hline
\end{tabular}

\subsubsection{Common Formula in the Market} Anomalies Test

For all the daily return in the Market anomalies test, it is determined by: 


$$
E\left(R_{t}\right)=\frac{P_{t}}{P_{t-1}}-1
$$

\subsubsection{Model}

Based on De Bond and Thaler's method (1985), the market anomalies are primarily determined by the significance of abnormal return. If there is no significant abnormal return in either watch window and event window for the study period, the stock return of the company can be sufficiently explained by the CAPM model as followed:

$\boldsymbol{E}\left(\boldsymbol{R}_{i t}\right)=\boldsymbol{R}_{\boldsymbol{f t}}+\mathrm{Q}\left[\boldsymbol{E}\left(\boldsymbol{R}_{\boldsymbol{m} t}\right)-\boldsymbol{R}_{\boldsymbol{f t}}\right]+\mathrm{S}, \mathrm{S} \sim \boldsymbol{N}(\mathbf{0}, \mathbf{1})$

Where: $1 . \mathrm{E}\left(\mathrm{R}_{\mathrm{it}}\right)$ as the daily return of the stock.

2. $\mathrm{Rft}$ as the daily return of the 10-year US T-bond.

3. $E\left(R_{m t}\right)$ as the daily return of the NASDAQ Composite Index.

4. $\varepsilon$ as a random error following the standard normal distribution.

\subsubsection{Steps for Determining the Type of Market} Anomaly and the Applied Statistics

Based on De Bond and Thaler's method (1985), three steps are used to determine the type of marketanomalies and applied statistic as follows:

1. Adjust the risk for the company's stock return in the watch window within the CAPMmodel (see formula 2.3.1) and determine the significance of the abnormal return in the watch window with the formula 2.3.2 2.3.4 as following:

$$
Z_{A R}=\frac{\sum_{T=1}^{T=N} A R_{t} / N}{\sigma_{A R} / \sqrt{N}}
$$

where

$$
\boldsymbol{A R} t=\boldsymbol{E}\left(\boldsymbol{R}_{i t}\right)-\hat{\boldsymbol{E}\left(\boldsymbol{R}_{i t}\right)}=\underset{\left.\left.\boldsymbol{R}_{\boldsymbol{f t}}\right)\right]}{\boldsymbol{E}\left(\boldsymbol{R}_{i t}\right)}-\left[\boldsymbol{R}_{\boldsymbol{f t}}+\mathrm{Q}\left(\boldsymbol{E}\left(\boldsymbol{R}_{m t}\right)-\right.\right.
$$

And

$$
\sigma_{A R}=\sqrt{\frac{\sum_{T=1}^{T=N} A R_{t}}{N-1}}
$$

Where $\mathrm{N}$ as the total trading day in either the watch window or event windows.

2. If the statistic AR is tested to be significant in the watch windows, the significance of $A R$ in event windows also to be tested within the formula 2.3.2 2.3.4. If the $A R$ in both the watch window and watch window are significant, there is an existing market anomaly in thecorresponding studied period.

3. For the study period whose AR are tested to be significant in both watch window and watchwindow, the type of the market anomalies is determined by the trend of time series of Cumulative Abnormal Return (CAR) and the CAR at each point is determined by the formula 2.3.5 as followed:

$$
C A R_{t}=\sum_{T=1}^{T=t} A R_{t} \quad(t=1,2,3 \ldots N)
$$

Where $\mathrm{t}$ as the $1 \mathrm{st}, 2 \mathrm{nd}, 3 \mathrm{rd} \ldots \mathrm{N}$ th day in the event window

Especially, if the market anomaly is the outperform momentum effect, it shall:

Have a positive and significant $A R$ in the event window.

There is an upward trend for the time series of CAR.

If the market anomaly is the underperform momentum effect, it shall:

1. Have a negative and significant $\mathrm{AR}$ in the event window.

2. There is a downward trend for the time series of CAR. If the market anomaly is the reverse effect, it shall:

1. There is a reverse trend for the time series of CAR and the reserve of CAR should occurbetween the 12th and 24th months of the event window.

\subsection{Alpha Magnitude Test}

The significance of the abnormal return might be accidental while the significance of alpha in theCAPM model would be more creditable. If the result of the alpha test is consistent with that of the abnormal return test in Section 2.3, it can further confirm that abnormal return is truly significant. Based on this, this paper proposes a reasonable hypothesis that:

1. In the same study period, both alpha and abnormal return shall be statistically significantin the same watch window and event window.

2. The sign of significant alpha and significant abnormal return shall be in the same direction, in other words, alpha and abnormal return shall be both positive or negative at the same time.

If alpha is not significant, it shall satisfy with the formula as following:

$$
\boldsymbol{R}_{i t}-\boldsymbol{R}_{\boldsymbol{f t}}=a+\mathrm{Q}\left(\boldsymbol{R}_{m t}-\boldsymbol{R}_{\boldsymbol{f t}}\right) \quad a \sim \boldsymbol{N}(\mathbf{0}, \mathbf{1})
$$

Where: 1. Rit as the daily return of the stock

2. Rft as the daily return of the 10-year US T-bond.

3. $\mathrm{R}_{\mathrm{mt}}$ as the daily return of the NASDAQ Composite Index.

4. $\varepsilon$ as a random error following the standard normal distribution

\section{EMPIRICAL RESULT}

\subsection{Result of the First VR Ratio Test}

By summarizing the frequency of overall significant VR ratio and applying the VR ratio method, Figure 3.1 demonstrates the frequency of overall significant VR ratio in each level and combining the frequency of the studied period 1 and studied period 2. Based on the result of 
Figure 3.1, there is an increasing trend of the frequency of overall significant VR ratio as moving from level 1 to level 6, which indicates that there is a "size effect" on the market efficiency of the NASDAQ.

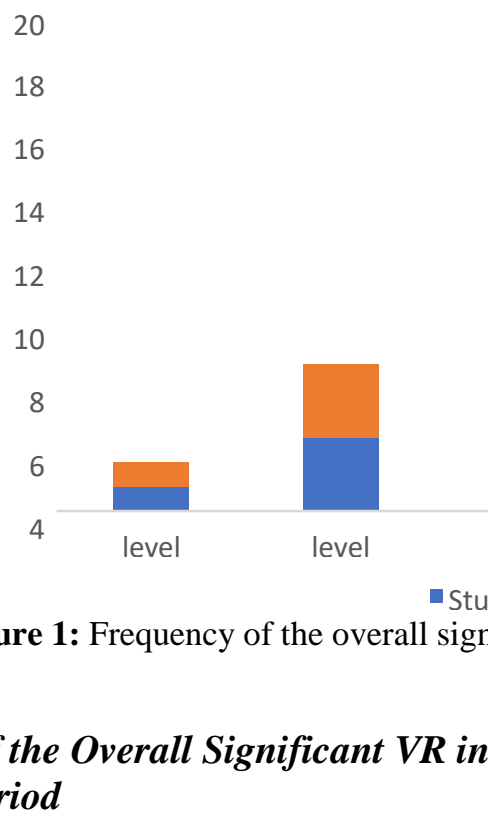

\subsection{Result of the
Each Lag Period}

For illuminating the pattern [15] of overall significant VR ratio, Figure 3.2-3.5 summarizes the magnitude of significant VR ratio [16] based on the lag period $(\mathrm{k}=$ 10,20,40,80) and levels. Figures 3.2-3.5 show that the overall significant VR ratio in each lag period is dominated by the contrarian pattern.

Also, shifting from level 1 to level 6 , the increasing trend of the frequency of significant VR ratio ineach lag period furtherly corroborates that there is a "size effect" on the frequency of significant VRratio.

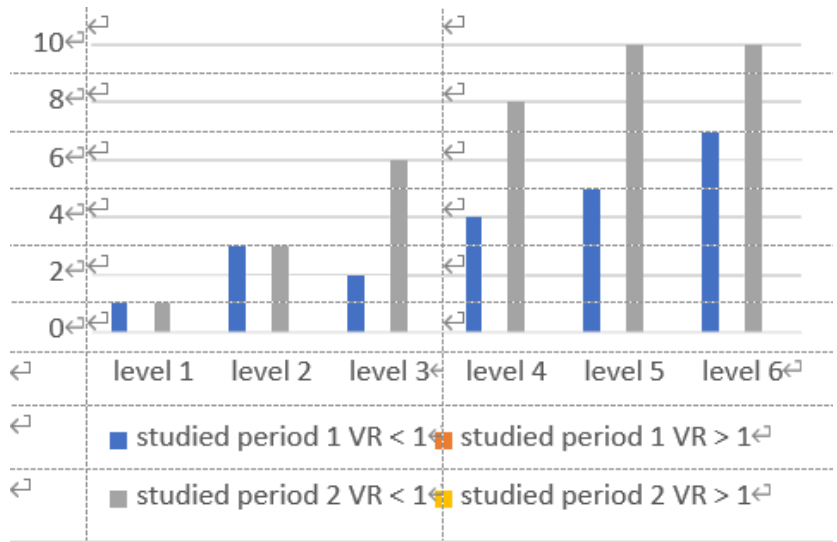

Figure 2: the frequency of VR ratio when $\mathrm{k}=10$

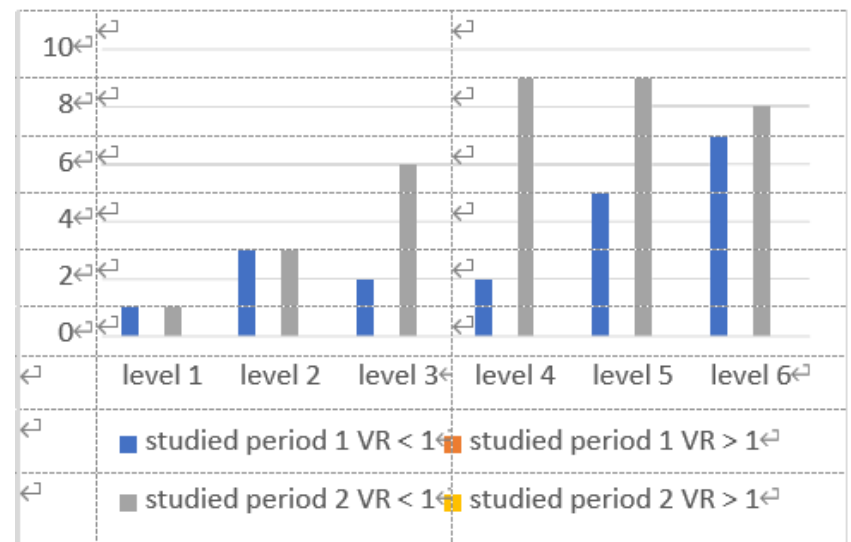

Figure 3: frequency of VR ratio when $k=20$

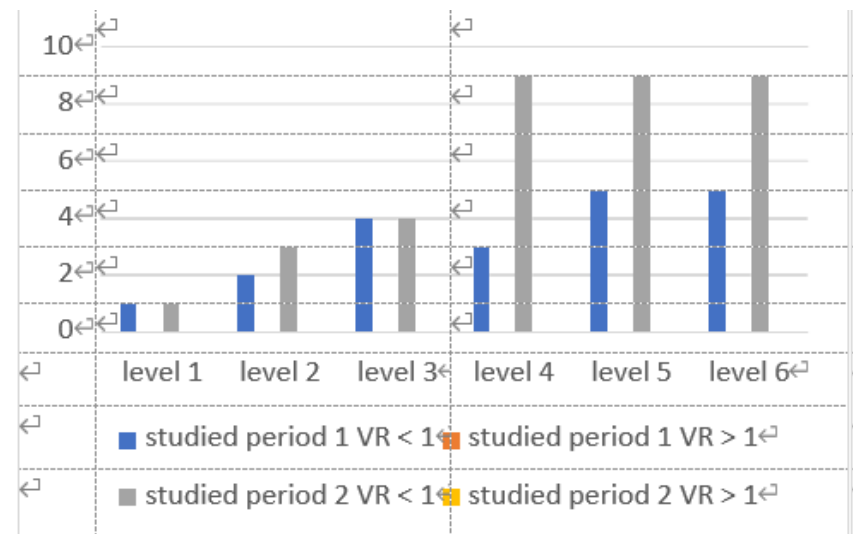

Figure 4: the frequency of VR ratio when $\mathrm{k}=40$ 


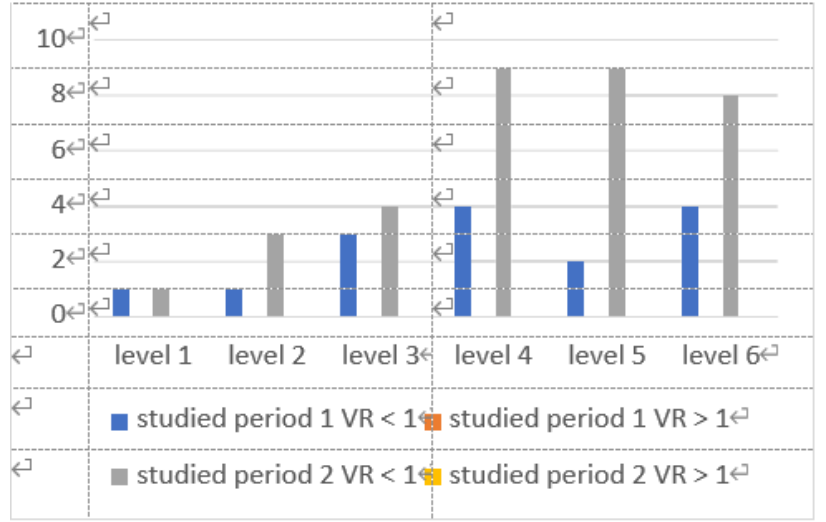

Figure 5: frequency of VR ratio when $k=80$

\subsection{Result of the Market Anomalies Test}

By summarizing the frequency of the three kinds of valid market anomalies, Figure 3.6 illuminates the frequency of three kinds of market anomalies from level 1 to level 6. According to Figure 3.6, most of the valid market anomalies are momentum effects. Among thevalid momentum effects, there is an increasing trend for underperform momentum effect as shifting from level 3 to level 6. Besides, the frequency of outperform momentum effect are increasing as shifting fromlevel 1 to level 3 and slightly decline as moving from level 3 to level 6. Based on the frequency of 3 kinds of valid market anomalies, there is only a "size effect" for the underperform momentum effect andthere is no particular and obvious pattern for the reserve effect and outperform momentum effect [17].

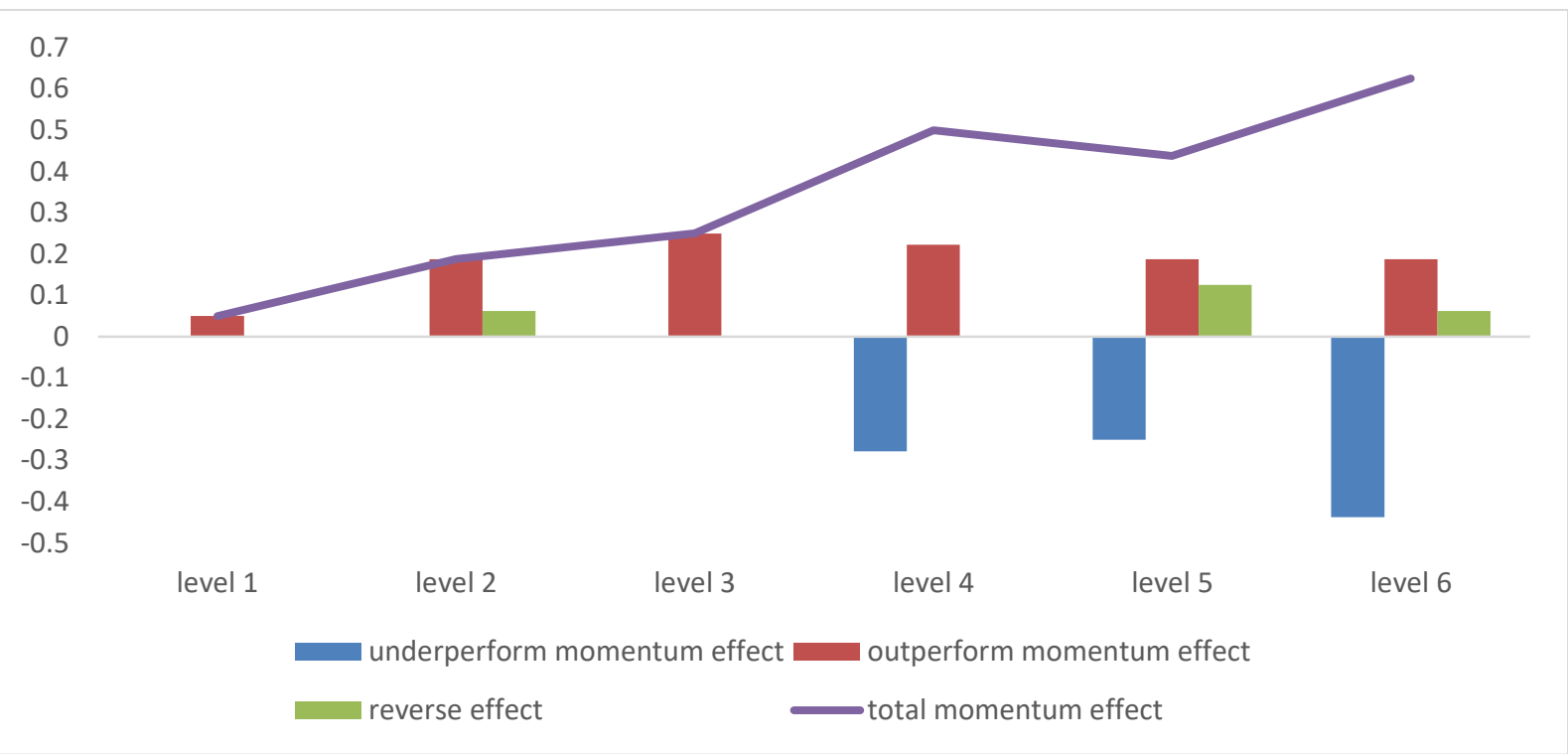

Figure 6 Frequency of Valid Market Anomalies in level 1 to level 6 based on the De Bondt \& Thaler's method

\subsection{Result of Alpha Magnitude Test}

Based on the Alpha's Magnitude, Figure 3.7 groups the valid Alpha's Magnitude [18] in each level by not significant alpha and significant alpha and summarizes the average magnitude of two groups from level 1 to level 6. According to Figure 3.7, there are two findingsabout the alpha magnitude in terms of the size of companies.
The first one is that there is a huge magnitude difference between the insignificant alpha group and the significant alpha group. While the second finding is that the magnitude of significant alpha from level 4 to level 6 is overall higher than the magnitude of significant alpha from level 1 to level 3, which indicates that the size of companies and the significance have an impact on the magnitude of alpha. 


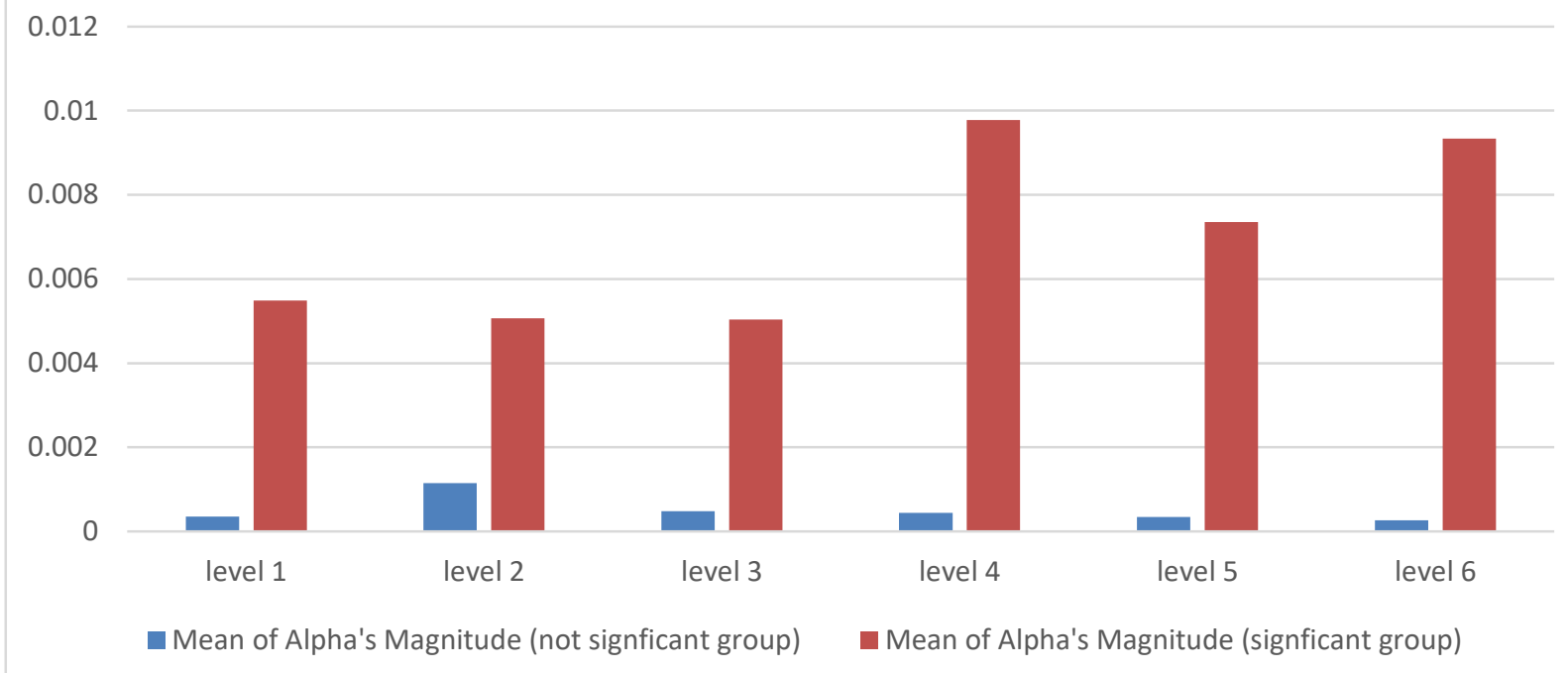

Figure 7: Mean of Valid Alpha's Magnitude from level 1 to level 6

\subsection{Result of Significant AR and Alpha Test}

Based on the reasonable hypothesis proposed in Section 2.4, Figure 3.8 summarizes the frequency distribution of the valid significant $A R$ and valid significant alpha [19] based on their sign and divided into the positive group and negative group. The frequency distribution shows that most of the observations match the hypothesis and most of the significant AR synchronizes with significant alpha within the CAPM model. Besides, Figure 3.8 shows that there is oneviolation [20] of the hypothesis in level 2, as the alpha of the observation isn't tested to be significant while the AR is tested to be significant.

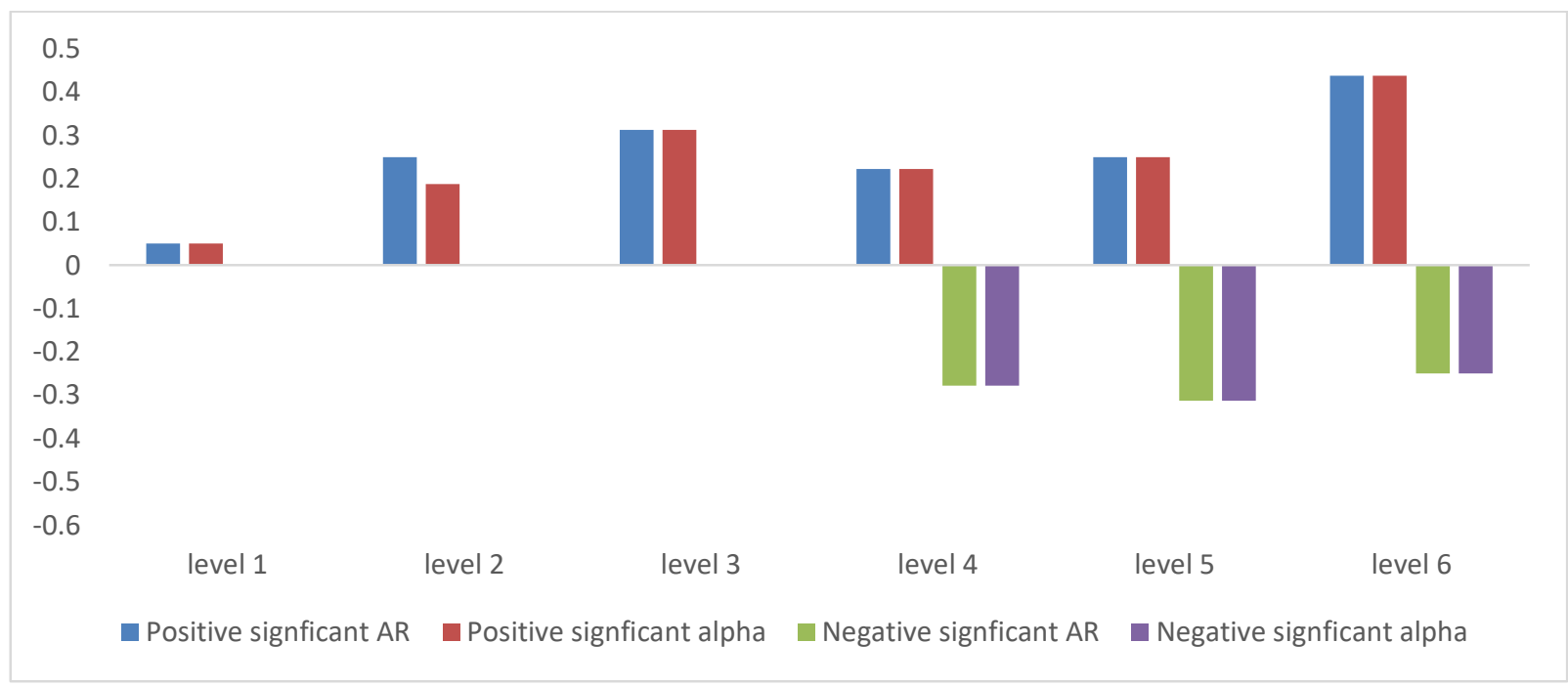

Figure 8: Frequency distribution of Valid Significant AR and Alpha in level 1 to level 6

\subsection{General Principle of Robust Check}

In order to test the robustness of the experimental results, a robust check that repeating the steps in part 2 is conducted and the robust group is based on the same sampling method and requirements. The difference between the primary group and the robust group is that the corresponding samples in the robust checking come from different industries.

\subsection{Robust Check Results}

For checking the robustness of the first result of the VR ratio test in Section 3.1.1, Figure 3.9 summarizes the frequency of the overall significant VR ratio based on the same method. Figure 3.9 demonstrates that the robust group has a similar result compared with the result in Section 3.1.1 as there is also an increasing trend of the frequency of overall significant VR ratio, which indicates that the founding about the "size effect" on the market efficiency is robust. 


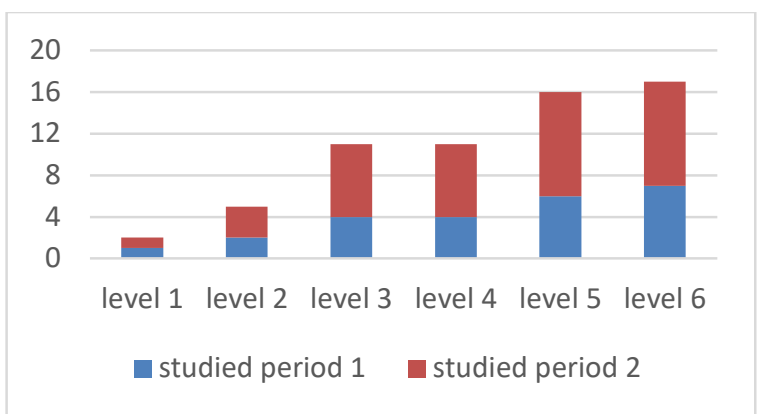

Figure 9: Robust checking of the Frequency of the overall significant VR ratio in each level

Besides, for checking the robustness of the result in Section 3.1.2, Figures 3.10-3.14 summarize the magnitude of valid significant VR ratio $^{33}$ and in each lag period from level 1 to level 6. The results of Figure 3.103.13 show that the pattern of significant VR ratio in each lag phase is still dominated by reversal pattern. Compared with the results in Section 3.1.2, the general situation is that the VR ratio of reverse mode still has an upward trend in all hysteresis periods. The difference is that from level 3 to level 6 , there are several irregular momentum patterns in the robust group. Generally, comparing the result between the primary group and robust group, the found that there is a size effect on the frequency of the contrarian pattern VR ratio is robust [21].

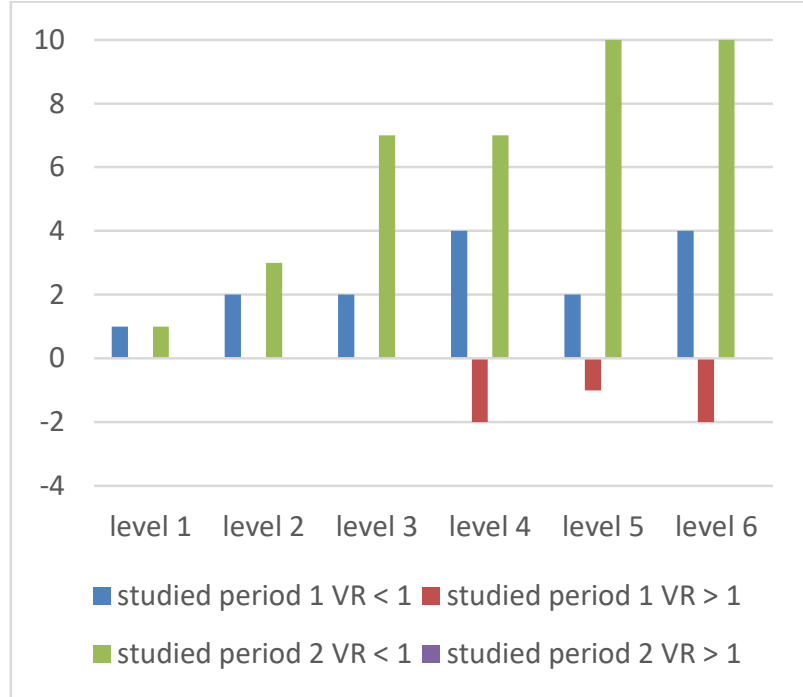

Figure 10 frequency of VR ratio when $\mathrm{k}=10$

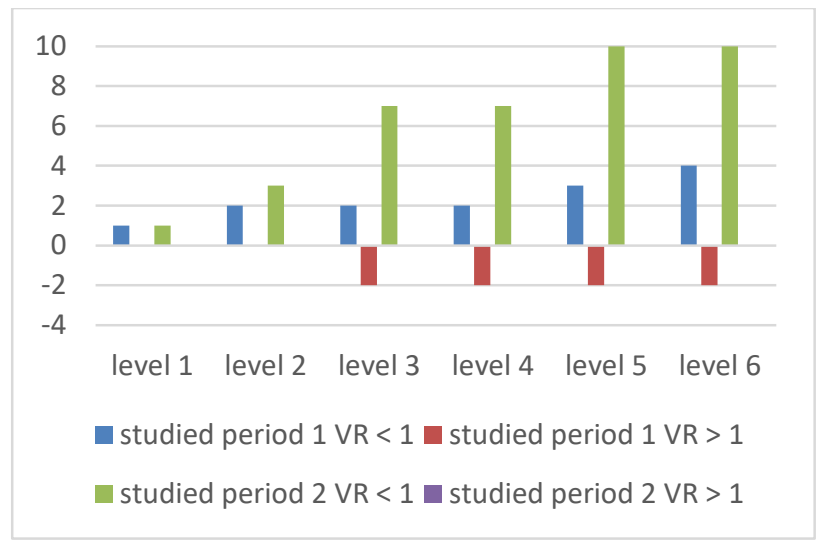

Figure 11 frequency of VR ratio when $k=20$

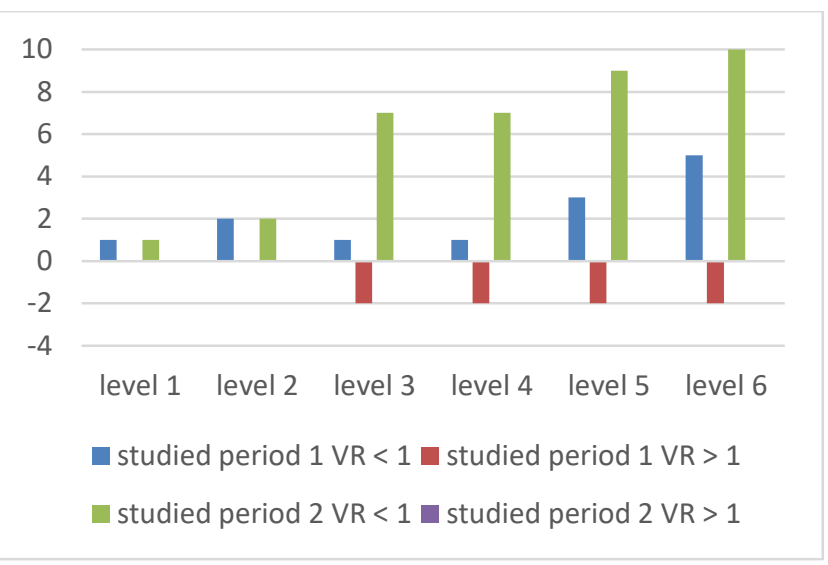

Figure 12 frequency of VR ratio when $k=40$

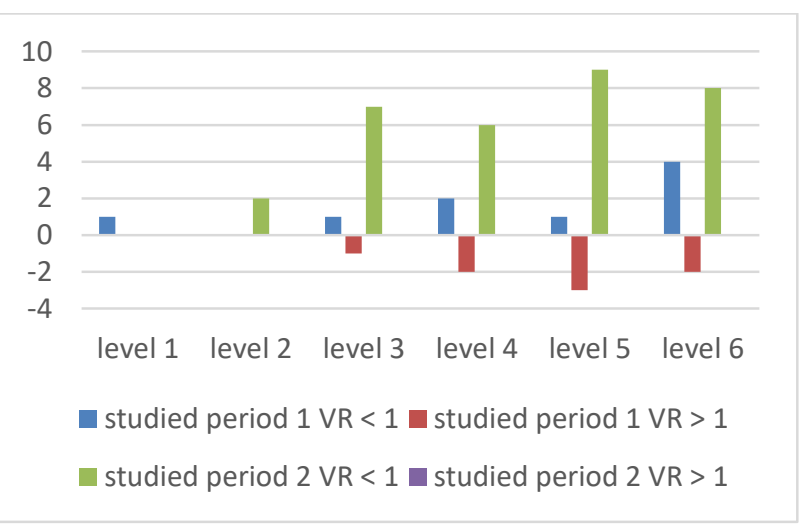

Figure 13 frequency of VR ratio when $k=80$

Use the similar method to test market anomalies and abnormal return. Generally, the found that there is a "size effect" on the frequency of underperform momentum effect is robust. And there is a similar pattern of the magnitude between not significant alpha and significant alpha, which indicates that the two founding about the alpha magnitude is robust. The robust test was consistent with the study. 


\section{CONCLUSION}

\subsection{Conclusion and Trading Strategies}

The research paper concludes that there is a "size effect" on NASDAQ's degree of market efficiency and frequency of market anomalies. According to the results of the primary group androbust group, after excluding the invalid observation, the results of the two groups show that the frequency of the overall significant VR ratio and the frequency of market anomalies are on the rise with the decline of the company size. Generally, the market efficiency of the NASDAQ does not reach weak form efficient market. Based on the frequency distribution of the valid significant VR ratio in each level,the market efficiency of middle-large size companies is higher than that of small-middle size companies [22]. Also, in terms of the frequency of market anomalies in each level, the pattern of the underperform momentum effect is different from outperform momentum effect. For the underperform momentum effect, there is an increasing trend for the underperform momentum effect as moving from level 3 to level 6 . However, for the outperform momentum effect, the frequency increases at the beginning and peak at the middle level [23] size as well as slightly declines after the peak. However, in terms of the probability that occurring the outperform momentum effect, the probability in level 2-3 is significantly higher than that of level 4.

\subsection{Future Research Outlook:}

As it is difficult to access to the earlier data, this research paper only studies the NASDAQ from 2009 to 2019. In the future, we hope to access to the earlier data, which includes the data from 2000-2007 or the data before 1999, so that we can do research about whether there is also a "size effect" on the market efficiency of NASDAQ in the earlier period.

\section{REFERENCES}

[1] The "size effect" in this paper is an analogy to the size effect discovered by Banz in 1980. The "size effect" in this paper means whether there is a certain phenomenon (like the degree of market efficiency and frequency of market anomalies) whose frequency of occurrence would vary due to the changes in the company's market capitalization and form an obvioustrend.

[2] Market anomalies in this paper is the collective term for outperform momentum effect, underperform momentum effect and reversal effect. See detail about three kinds of effect in section 2.3.4.

[3] In De Bondt and Thaler's method (1985), two steps to build up the "winner portfolio" and "loser portfolio" are as followed:
Step 1: Taking 5 year as a studied period for each stock in the sample and testing whether having significant CAR in the first two year after adjusted the risk by CAPM for each stock.

Step 2: ranking the stocks that has significant CAR in the first year in descending order. The first 35 stock will be assigned in the "winner portfolio" and the last 35 stocks will be assigned to "loser portfolio".

[4] There is a difference between Jegadeesh and Titman's approach and De Bond and Thaler's approach on the way to get thedata for calculating CAR. After building the winner portfolio and loser portfolio, Jegadeesh and Titman (1933) holds the winner portfolio and loser portfolio in the following three year to test whether there is significant CAR for each stock in thestudied period. However, De Bond and Thaler (1985) used the historical data of the stock in the following three year as the data resource to calculate the $\mathrm{CAR}$.

[5] The risk-adjustment model applied in the Banz's paper is CAPM model.

[6] There is a difference between Jegadeesh and Titman's approach and De Bond and Thaler's approach on the way to get thedata for calculating CAR. After building the winner portfolio and loser portfolio, Jegadeesh and Titman (1933) holds the winner portfolio and loser portfolio in the following three year to test whether there is significant CAR for each stock in thestudied period. However, De Bond and Thaler (1985) used the historical data of the stock in the following three year as the data resource to calculate the $\mathrm{CAR}$.

[7] quite period is the period between two extreme macroeconomic event and the extreme macroeconomic event to beexcluded in this paper are the subprime mortgage crisis in 2008 and the COVID-19 pandemic began in 2020 .

[8] The data regarding the market cap at the year-end is from Yahoo! Finance. And the level to which a company is assigned is determined by the company's average market capitalization in studied period one and studied period two.

[9] ${ }^{1}$ AMC here in the table defined as Average Market Capitalization in each studied period, which is determined by the formula: $A M C=$

[10] the market cap data refers to the market cap at year end and price referred to the daily close price of each company. 
[11] The symbol of stock represents the company. For example, the symbol of Microsoft Corporation is MSFT.

[12] NASDAQ composition is a market value weighted index including all the companies listed in NASDAQ. The website of composition of NASDAQ composition is as followed:https://www.investing.com/indices/nasda q-composite-components

[13] Based on the VR ratio initiated by Lo and MacKinlay (1988), the lag $\mathrm{k}$ in the VR ratio test should be one week, two weeks,four weeks, eight weeks and sixteen weeks. As 1 week is consisted of 5 trading day, the lag $\mathrm{k}$ should be $5,10,20,40,80$ days, respectively.

[14] All the return are daily basis, and all the price refers to the daily close price. All data about price comes from Yahoo!Finance.

[15] The pattern of significant VR ratio is associated with the magnitude of the VR ratio. "Momentum pattern" is defined to be the significant VR ratio greater than 1 and "contrarian pattern" is defined to be the significant VR ratio smaller than 1 (Linton, 3.3.5 Variance Ratio Test, 2019).

[16] The significant VR ratio being summarized comes from the studies period that is "overall significant"

[17] For avoiding overlapping and clearly presenting the frequency of 3 kinds of Valid Market Anomalies, the frequency ofunderperform momentum effect are displayed in negative axis. The frequency of each kind of market anomalies in each level are determined by valid observation of market anomaliestotal valid observations in the corresponding level. Due to exclusion of invalid observation, the total valid observations in the corresponding level not always equal to total observation of 20 .

[18] Valid Alpha's Magnitude is determined by the valid observation. Only the Alpha from valid observation can be included in the alpha magnitude test.

[19] Due to exclusion of invalid observation, the calculation of themean of valid Alpha's Magnitude is based on the total valid observations in the corresponding level.

[20] For avoiding overlapping and clearly present the frequency distribution of the positive and negative group, the frequency distribution of the negative group is displayed in the negative axis.

[21] For avoiding overlapping and clearly presenting the frequency of momentum pattern, the frequency distribution of the momentum-pattern VR ratio is displayed in the negative axis.

[22] "Middle-large size companies" refers to the companies from level 1-3 and the "small-middle size companies" refers to thecompanies from level from level 4-6.

[23] The "middle level" refers to the companies from level 3 (middle level) to level 4 (middle small level). 